\title{
超超临界汽轮机设备常见故障及处理方法
}

\author{
王亚江 \\ 国电投周口燃气热电有限公司 \\ DOI:10.32629/hwr.v4i1.2650
}

[摘要] 目前我国引进消化生产的超超临界1000MW机组均由上海电气、东方电气和哈尔滨电气三大动力集团公司生产, 上海电气生产机型 为引进德国西门子技术, 东方电气生产机型为日本日立公司技术, 哈尔滨电气生产机型为日本东芝技术。目前各发电厂使用口碑均认为上海 电气西门子机型优于日立和东芝, 本课题主要研究方向以上海电气生产 $1000 \mathrm{MW}$ 机型为主。本文首先以上汽超超临界机组为例对汽轮机本体 及主要参数做了全面的介绍,然后就汽轮机设备常见故障进行原因分析,并提出了处理方法。可为同类型机组的日常维护及定期检修提供技 术参考和指导。

[关键词] 本体概况; 参数; 常见故障; 原因分析; 处理方法

\section{1 汽轮机本体概况及参数}

1.1 超超临界机组汽轮机本体概述 (以上汽机组为例)

上海电气1000MW超超临界机组汽轮机是由上海汽轮机有限公司和德国 SIEMENS公司联合设计制造的组合积木块式HMN机型, 为超超临界、一次中间 再热、单轴、四缸四排汽、双背压、八级回热抽汽、反动凝汽式汽轮机。

该型汽轮机的本体部分由四个汽缸组成, 即一个高压缸、一个双流中 压缸和两个双流低压缸。高、中、低压转子均采用无中心孔整锻转子, 具 有刚性好, 应力小的特点。通过刚性联轴器将四个转子连为一体, 低压转子 B通过刚性联轴器与发电机转子相连, 组成的汽轮发电机总长度约为 $49 \mathrm{~m}$, 高度约为 $7.75 \mathrm{~m}$, 宽度约为 $16 \mathrm{~m}$ 。

除高压转子由两轴承支撑外, 其它转子均由单轴承支撑。五个轴承座 均直接支撑在基础上, 不随机组膨胀移动, 并能减少基础变形对轴承载荷 及轴系对中的影响。其中\#2轴承座内装有径向推力联合轴承, 且机组的绝 对死点和相对死点均在高中压之间的\#2轴承座上。整个通流部分由高压、 中压和低压三部分组成, 共设 64 级, 均为反动级。高压部分 14 级。中压部分 为双向分流式, 每一分流为 13 级, 共 26 级。低压部分为两缸双向分流式, 每 一分流为 6 级, 共 24 级。

同时高压缸采用了先进的补汽阀技术, 各汽门与汽缸直接连接, 无导 汽管。采用节流调节、全周进汽, 相对于喷嘴调节不存在高温叶片强度和 汽流激振问题, 是大功率汽轮机最安全可靠的配汽方式, 并提高了机组运 行的经济性和安全可靠性。

\section{2 汽轮机主要技术参数}

型号：N1000-26.25/600/600 (TC4F), 型式: 超超临界中间再热凝汽式、 单轴、四缸四排汽汽轮机, 额定功率: $1000 \mathrm{MW}$, 最大功率: $1049.85 \mathrm{MW}$, 额定 转速: $3000 \mathrm{r} / \mathrm{min}$, 旋转方向: 自汽机向发电机看顺时针方向, 主汽门前额定 压力: $26.25 \mathrm{MPa}$ (a), 主汽门前额定温度: $600^{\circ} \mathrm{C}$, 主蒸汽流量: $2943 \mathrm{t} / \mathrm{h}$, 高 压缸排汽压力: $5.95 \mathrm{MPa}(\mathrm{a})$, 再热汽门前额定压力: $5.35 \mathrm{MPa}(\mathrm{a})$, 再热汽门 前额定温度: $600^{\circ} \mathrm{C}$, 再热蒸汽流量: $2465.4 \mathrm{t} / \mathrm{h}$, 平均背压: $6.2 \mathrm{kPa}$ (a), 给 水温度: $295.1^{\circ} \mathrm{C}$, 低压缸末级叶片长度: $1146 \mathrm{~mm}$, 调节系统型式: 数字式电 液调节系统, 允许电网周率波动: $47.5 \sim 51.5 \mathrm{~Hz}$, 水葲驱动方式: $2 \times 50 \%$ 容 量, 回热级数: 三高 (双列) 、四低、一除氧, 配汽方式: 全周进汽/节流调节, 盘车转速: $30 \mathrm{r} / \mathrm{min}$. , 汽轮机总长: 约 $28 \mathrm{~m}$, 运行层相对零米标高: $17 \mathrm{~m}$ 。

\section{2 设备常见故障及处理}

2. 1 转子振动异常

2. 1.1 旋转部件不平衡

原因分析及处理: (1) 轴有永久变形 (轴弯曲)。可以联系生产厂家进
行修理; (2) 启动时暖机方式不当, 造成轴弹性弯曲。停机重新启动或降 低转速延长暖机时间; (3) 叶片、围带不均匀腐蚀, 机械磨损或结垢。更 换腐蚀或磨损严重的叶片、围带, 消除结垢, 然后转子找平衡; (4) 转子 上有活动零件、联轴器或者转子上的其它零件不平衡。对零件找平衡, 或连同转子一起找平衡; (5) 转子部件在高转速时, 有不对称的位移现 象。在高转速下找动平衡; (6) 由于电磁冲击所造成的靠背轮松动。重 新紧固靠背轮螺栓。

\subsection{2动静部件的径向、轴向摩擦}

原因分析及处理：（1）由于缸体的热变形和半缸一全缸变形量。调整 时考虑缸体变形量; (2) 由于真空的改变造成排汽口的变形。运行时调定 合适的真空值; (3) 安装不佳。按照检修工艺严格操作。(4) 热膨胀异常。 合适的运行操作方式; (5) 推力轴承瓦块磨损。更换磨损量超标推力轴承 瓦块; (6) 隔板变形。更换变形量超标的隔板。

2.1.3机组中心异常

原因分析及处理: (1) 轴承座热变形。对轴承座进行调整, (2) 排汽室 真空变化。运行时调定合适的真空值; (3) 基础变形或沉降。对基础进行 检查调整; (4) 联轴器紧固不佳。按联轴器紧固紧固工艺重新紧固。

\subsection{4 油膜振荡}

原因分析及处理：（1）由于中心异常改变轴承载荷。重新调整中心; (2) 轴承润滑油温度较低。按规程要求调整轴承润滑油温度; (3) 轴承润滑 油流量增加。调整润滑油流量; (4) 轴瓦间隙太大, 使油膜建立不起来。调 整轴承轴瓦间隙; (5) 油质不良。换油, 并对润滑油建立可靠的监督制度。

2.2 轴承排油温度或瓦块金属温度升高

原因分析及处理：（1）由于中心异常改变轴承载荷。检修中根据中心 标准对转子中心进行调整; (2) 油质不合格。油质不合格时应加强滤油或 换油, 油质乳化应故障停机; (3) 轴承瓦块巴氏合金磨损, 轴承间隙减少。 检修时根据要求对轴承调整处理; (4) 轴承过负荷、超速或发生强烈振动。 监视轴承、转子异常; (5) 轴封漏气大。保证凝汽器真空的前提下, 可适当 调低轴封汽压力。

2. 3推力轴承瓦块金属温度升高

原因分析及处理:（1)推力盘变形。对推力盘进行检查, 处理; (2) 中 心异常。调整转子中心至检修管理目标值; (3) 推力轴承轴向间隙减少。 调整推力轴承轴向间隙至设计值。

2.4 机组性能降低

原因分析及处理：（1）内部间隙增加。检修中调整间隙数值; (2) 喷嘴 或动叶上结垢。清理喷嘴或动叶的结垢物; (3) 喷嘴或动叶上腐蚀或损坏。 


\section{检修隔离闭锁系统在变电站检修过程中的应用}

\section{郭旭}

国网内蒙古东部电力有限公司通辽供电公司

DOI:10.32629/hwr.v4i1.2689

[摘 要] 为了防止由于人为因素而在操作维护区域中出现误送电事故,在维护过程中必须在维护人员和操作人员之间建立连贯的关系。变电站 通过在维护设备与带电设备断开连接的位置添加隔离设备, 可以将维护设备与带电设备完全分开。隔离闭锁系统的应用, 改变当前送电操作, 由 操作人员控制输电操作的情况,特别是对于同时执行许多维护操作的大型综合停电，这可以明显防止误送电的情况发生。

[关键词]隔离闭锁系统; 变电站; 检修; 应用

防误闭锁系统的技术发展越来越精细成熟, 它的运行稳定性也在逐渐 提高, 它实现了对倒闸整个运行过程的控制。但是, 目前在变电站维护操作 的安全措施中仍然存在漏洞和潜在的安全隐患。例如, 在变电站电气替换 设备的维护中, 维护中的设备的操作权限在操作员的控制之下, 缺乏严格 的约束力。由于设备检修期间的安全事故屡有发生, 主要原因是对检修作 业过程中的危险源缺乏有效技术手段予以保障, 在这种情况下引入了检修 隔离闭锁系统。

\section{1 检修隔离闭锁系统}

1. 1 检修隔离闭锁系统结构组成

检修隔离闭锁系统主要包括维护控制面板控制, 主机隔离管理的维护 和授权密钥。它的应用通常分为两种模式, 就建设新变电站而言, 控制面板 较旧, 授权密钥也存在老化的现象需要更换。通常使用带有控制面板的检 修隔离闭锁设备以及整个设备的维护。相反, 当不需要更换替换设备时, 通常使用单独的锁定隔离设备。

\section{2 系统的工作原理}

当检修隔离闭锁系统进入维护模式时, 系统会自动生成维护检修任务, 一次性关闭要隔离的设备, 然后将其切换到隔离设备中。检修人员通过系 统生成的指令将设备与授权密钥相关联, 并向操作系统人员提供相关的授 权密钥给维护人员进行存储 ${ }^{[1]}$ 。维护检修过程完成后, 检修人员将授权密 钥返回给系统操作员。操作员在系统的控制面板上放回钥匙, 系统自动打 开, 设备继续运行。在设备系统检修维护的过程中, 检修人员应事先制定详 细的检修计划, 分析变电站的实际运行过程, 预测可能发生的事故, 并为系 统范围的应用进行一定程度上的调整。

应当仔细区分解锁和开锁功能之间所有细节部分的情况, 并且钥匙只 能在维护检修期间用于解锁使用。在进行检修的时候, 操作人员不得对关 联的维护检修设备执行其他操作, 并且检修人员可以通过授权密钥对设备 进行维护检修。当系统开始对检修任务启动时, 将在隔离闭锁控制面板上 模拟相关设备, 保障检修设备在进行检修的期间正常运行。操作人员将授
权钥匙和主控制设备带到检查现场, 以锁定需要检查的设备。操作人员可 以将授权密钥提供给检修人员。检修过程结束后, 操作人员收回钥匙并恢 复设备的正常运行, 向上级报告维修结果, 变电站管理人员要提出合理的 管理计划, 让这一类问题的发生次数尽量减少 ${ }^{[2]}$ 。

\section{3 系统的特点}

基于图形设计的概念, 对检修隔离闭锁系统进行了研究。系统通过图 形界面隔离显示资源风险和设备信息。隔离和闭锁管理系统的开发基于现 有的防错误系统平台。该系统可以支持图形方法, 无需手动输入即可生成 锁定操作序列, 从而减少了人员的工作量 ${ }^{\left[{ }^{3]}\right.}$ 。系统可以将分区许可的顺序 传递给计算机密钥, 并接收计算机密钥返回的隔离锁定执行信息。

当系统测试时, 很明显需要解除双方的部分隔离措施和责任, 与此同 时它可以自动获取与其关联的工作单, 以防止出现漏掉工作单。该系统可 以执行各种维度的查询分析, 例如专业, 团队, 执行时间等方面的详细查 询。此外, 系统支持隔离设备上的正向查询以及隔离设备的锁定情况。该 系统实现对已执行或已完成的隔离活动以及隔离历史任务的统一管理, 相 关检修资料和人员的查询。

1.4 检修系统的授权和管理

检修隔离主机收到任务后, 可以在检修隔离主机中选择适当的操作任 务, 并选择授权密钥, 主机将自动解锁所选授权密钥机制, 检修人员可以移 除授权密钥进行操作。有关检索和授权密钥的更多信息, 可以在主机以及 五防计算机上查询。可以预先设置检修负责人的密钥。使用检修负责人的 密钥, 可以向工作团队成员发放工作卡, 以确保身份的唯一性 ${ }^{[4]}$ 。记录团队 成员进出现场的管理, 以及进出时间, 实现工作成员的出勤管理。

\section{2 检修隔离闭锁系统的优势}

2.1管控手段的优势

当检修人员对设备进行检修的过程中, 相关操作人员禁止与相关设备 进行操作, 并且将操作检修设备权限的从 “人为控制” 更改为 “机器系统 控制”。这样做可以有效的解决检修时检修人员和操作人员对设备的控制
对喷嘴或动叶损伤情况评估, 进行修理; (4) 蒸汽状态异常, 如排气状况、 真空等。调整运行工况。

2.5 级间压力变化

原因分析及处理:（1）喷嘴或动叶上结垢。检修时清理喷嘴或动叶上结 垢; (2) 喷嘴或动叶上腐蚀或损坏。检修时处理喷嘴或动叶上腐蚀或损坏。

2. 6 缸体或结合面蒸汽泄漏

原因分析及处理：（1）缸体的热变形或结合面变形。联系生产厂家处 理; (2) 安装不佳。根据检修工艺要求正确安装; (3) 螺栓伸长量 (力矩) 不足。采用正确的螺栓伸长量 (力矩) 安装; (4) 轴封汽封间隙增大。调整
轴封汽封径向间隙至管理目标值; (5) 密封垫片老化。密封垫片的更换。 2. 7 水冲击

原因分析及处理:（1）由于误操作或设备异动造成在机组负荷突然变 化中将水从热井中带入或蒸汽温度偏低。正确合理的运行操作; (2) 轴封 管道或疏水管道回流。安装疏水器等措施避免疏水回流。

[参考文献]

[1]汽轮机原理 [M].北京: 中国电力出版社,1992:6.

[2]汽轮机设备及运行[M].北京: 中国电力出版社,2004:12.

[3]汽轮机设备及及其系统[M].北京:中国电力出版社,2007:09. 